\title{
Mature fine tailings drying — technology update
}

\author{
P.S. Wells Suncor Energy Inc., Canada
}

A. Revington Suncor Energy Inc., Canada

O. Omotoso Suncor Energy Inc., Canada

\begin{abstract}
As part of an industry wide technology development effort led by the production operators of the Athabasca Oil Sands of northeastern Alberta, Canada, a significant step forward in full scale application of the thin lift dewatering process known as mature fine tailings (MFT) drying (Wells and Riley, 2007) has been made by Suncor Energy Inc. This new process has demonstrated, at full production scale, dewatering performance that was previously considered to be technically unfeasible. Advances in both the chemical additives used as well as the mixing and depositional controls resulted in performance improvements sufficient to allow the full scale adoption of the technology by Suncor Energy Inc. This paper outlines these advances as well as the improved understanding in the behaviour of the materials.
\end{abstract}

\section{Introduction}

Dealing with accumulations of fluid fine tailings known as MFT by operations in the oil sands of northeastern Alberta, Canada has been a long standing challenge. Decades of research and technology development have produced excellent fundamental understandings of the science related to the behaviour of these fine tailings materials, but have not produced an operational solution to the increasing volumes in the fluid storage ponds.

Over the past decade, changes in the global oil markets have affected the economic landscape in the oil sands industry resulting in increased focus on the development of the resource both by production operators as well as the general public. This public focus is reflected in global media reports, reviews and commentaries by NGO's and outside technical experts, as well as enhanced regulatory focus. In response to this changing landscape, operators and associated research organisations have increased efforts to provide tangible improvements to the industry which would allow for the continued safe and effective development of this valuable Canadian resource known as the Athabasca oil sands.

Suncor's tailings reduction operations (TRO) represents the first major tailings technology adopted at production scale by an oil sands operator that is a significant departure from previous technologies. These previous technologies, known alternately as consolidated/composite tailings (CT) or non-segregating tailings (NST), have been in use in various forms since the mid-1990s and are based on producing non-segregating mixtures of both coarse and fine tailings streams. The new TRO process separates these two streams. The fines stream is treated with the technology known as MFT drying, more specifically as polymer MFT drying. It has now been demonstrated at full production scales and, in April to November 2010, resulted in the dewatering of over 3 million dry metric tonnes of fines representing a reduction of some 8 million cubic metres of fluid MFT from pond storage. This technology now forms the basis for Suncor's continued operations, and is the first technology to meet all regulatory requirements including the new regulation from Alberta's Energy Resources Conservation Board (ERCB) known as Directive 74.

\section{$2 \quad$ Significant advances since 2007}

As a technology for dewatering fine tailings MFT drying, as conceived and tested in 2007, was restricted to the evaporation potential of the deposition area (Wells and Riley, 2007). The addition of hydrated lime and gypsum, while capable of increasing the strength of the material to be deposited, was not capable of releasing water from the matrix other than through evaporation or freeze/thaw processes. 
Shortly after the Paste '07 Seminar, a collaborative research project was undertaken with the chemical company SNF Inc. to investigate alternative chemicals for the MFT drying process. Suncor supplied the performance requirements for an additive, focusing on strength gain and resistance to shear. A secondary objective was enhanced dewatering, as several previous attempts to flocculate MFT (Golder, 2007; Matthew 2008; Jeeravipoolvam, 2008) required dilution of the material prior to mixing with the flocculant, which then only achieved clay to water ratios similar or slightly less than that found in the source MFT. Commercial application of polymeric flocculation in oil sands is restricted to low solids content fine tails, and these processes have been unable to collapse the clay matrix any further than that found in the settling ponds.

During the course of SNF Inc.'s bench scale tests, a new polymer type, developed by SNF Inc. for this test programme, showed promise in both strength gain and shear resistance. In addition, the polymer appeared to promote initial dewatering of the MFT shortly after mixing by generating a highly permeable floc structure. This meant that the process might no longer rely on evaporative drying alone, but rather a combination of initial accelerated dewatering with the release of supernatant water down the deposit slope over time, in addition to evaporation. No dilution of the MFT was required beyond the polymer make up water and the polymer could be injected in-line without the use of a thickener. The polymer was found to be effective for MFT up to $40 \%$ solids by weight with up to $100 \%$ fines $(<44 \mu \mathrm{m})$, and roughly a 0.4 clay:water ratio.

The first field test in late 2007 produced surprising results, allowing for $20-30 \mathrm{~cm}$ lifts to reach $80 \%$ solids in less than 10 days. Given the weather conditions at the time, at least $85 \%$ of the total water removed from the MFT was released as free water given that the potential evaporation rates were too low to account for the dewatering rate. This initial success appeared to be robust and relatively insensitive to changes in fluid density and injection locations.

Subsequent testing began to illustrate, however, that there was a basic understanding of the behaviour of the flocculated material that was not obtained during the initial laboratory or field tests. Deposition was attempted with lower levels of control on the density and flow rates of the source MFT, resulting in a wider variety of deposit dewatering rates. Many of these deposits did not behave as previously observed, and several attempts at enhancing the dewatering performance through additional mixing, changes in the deposition mechanisms, or mechanical manipulation of the deposits met with limited success. It became apparent that more testing was required to determine the actual mechanisms and controls on performance of this flocculation process.

\section{Investigation of undiluted MFT flocculation}

An objective of the process was to manipulate the MFT floc structure such that initial dewatering was maximised and the MFT gained just enough strength to stack in a thin lift when deposited on a shallow slope. Dewatering was to occur as a function of mixing and applied shear during pipeline transport as well as on the deposition slopes.

Bench and pilot scale experiments were conducted to replicate the field observations and to investigate the dewatering potential as a function of polymer dosage, injection type, mixing, total applied shear and clay-towater ratio of the MFT. The experiments highlighted several key factors:

- Polymer dosage was best determined by clay content, measured as clay activity using methylene blue adsorption method.

- Mixing of the polymer-treated MFT using laboratory or in-line static mixers can result in less than optimum dewatering potential and stacking in the deposition slopes.

- Shear energy applied to the flocculated materials can greatly affect the dewatering and strength performance. Insufficient shear often creates a high strength material with minimal dewatering, while excess shear reduces the strength to MFT-like strengths with reduced permeability and dewatering.

\subsection{Polymer dosage}

Although it is recognised that the rheology of flocculated systems is governed by the finest particles in slurry, in most mining applications polymer is added on a gram per tonne of solids basis and this is often 
adequate for a homogeneous slurry. However, fine tailings are deposited in segregating ponds and the mineral size distribution of MFT depends on the sampling depth. Therefore dosing on a solid basis would often result in an under-dosed or an overdosed situation regarding maximum water release. This is highlighted in Table 1 for three MFT samples that show large variations in the optimum SNF-polymer dosage on solids or fines basis, but consistency in terms of clay content. The MFT samples were sourced from two Suncor ponds at different depths and with similar water chemistries.

Table 1 Optimum polymer dosage for maximum initial water release

\begin{tabular}{ccrrrrr}
\hline Sample & $\begin{array}{c}\text { Wt\% } \\
\text { ID }\end{array}$ & $\begin{array}{c}\text { Solids } \\
\text { on Solids }\end{array}$ & $\begin{array}{c}\text { Wt\% Fines } \\
\text { on Solids }\end{array}$ & $\begin{array}{c}\text { Optimum Polymer Dosage } \\
\text { Solids) }\end{array}$ & $\begin{array}{c}\text { (g/t of Fines } \\
<\mathbf{4 4} \boldsymbol{\mu m} \text { ) }\end{array}$ & $\begin{array}{c}\text { (g/t of } \\
\text { Clay) }\end{array}$ \\
\hline MFT A & 44.0 & 48.9 & 59.8 & 800 & 1,424 & 1,742 \\
MFT B & 32.6 & 78.9 & 89.3 & 1,200 & 1,428 & 1,616 \\
MFT C & 22.3 & 99.6 & 98.8 & 1,700 & 1,707 & 1,693 \\
\hline
\end{tabular}

$* \mathrm{Wt} \%$ clay is based on the surface area determined from methylene blue adsorption and could be greater than $100 \%$ for high surface area clays (Omotoso and Mikula, 2004).

\subsection{Rheology of flocculated MFT}

A simple static yield stress progression over time is being used to evaluate optimal yield stress for deposition and water release in the laboratory (Spicer and Pratsinis, 1996), pilot and field experiments. The shear yield stress was measured by a Brookfield DV-III rheometer. The water release was measured by decanting the initial water release and by capillary suction time (CST). The capillary suction time measures the filterability of a slurry and it is essentially the time it takes water to percolate through the material and a filter paper medium, and travel between two electrodes placed $1 \mathrm{~cm}$ apart. The method is often used as a relative measure of permeability.

Figure 1 shows an optimally dosed MFT ( $800 \mathrm{~g} /$ tonne of solid and a $0.45 \%$ polymer solution) mixed in a laboratory jar mixer with the rpm calibrated to the mean velocity gradient. The figure shows the shear yield stress progression curve for a $40 \mathrm{wt} \%$ solids MFT. The polymer was injected within a few seconds while stirring the MFT at $220 \mathrm{~s}^{-1}$. Mixing continued at the same mean velocity gradient until the material completely broke down. At each point on the curve, mixing was stopped and the yield stress measured. Water release during mixing is often dramatic and was clearly observed. The extent of water release is given by a test known as the capillary suction time. A low suction time correlates to high permeability and a high suction time correlates to low permeability. MFT dosed at $800 \mathrm{~g} /$ tonne of solid released the most water and about $20-25 \%$ of the initial MFT water was released at the lowest CST. 


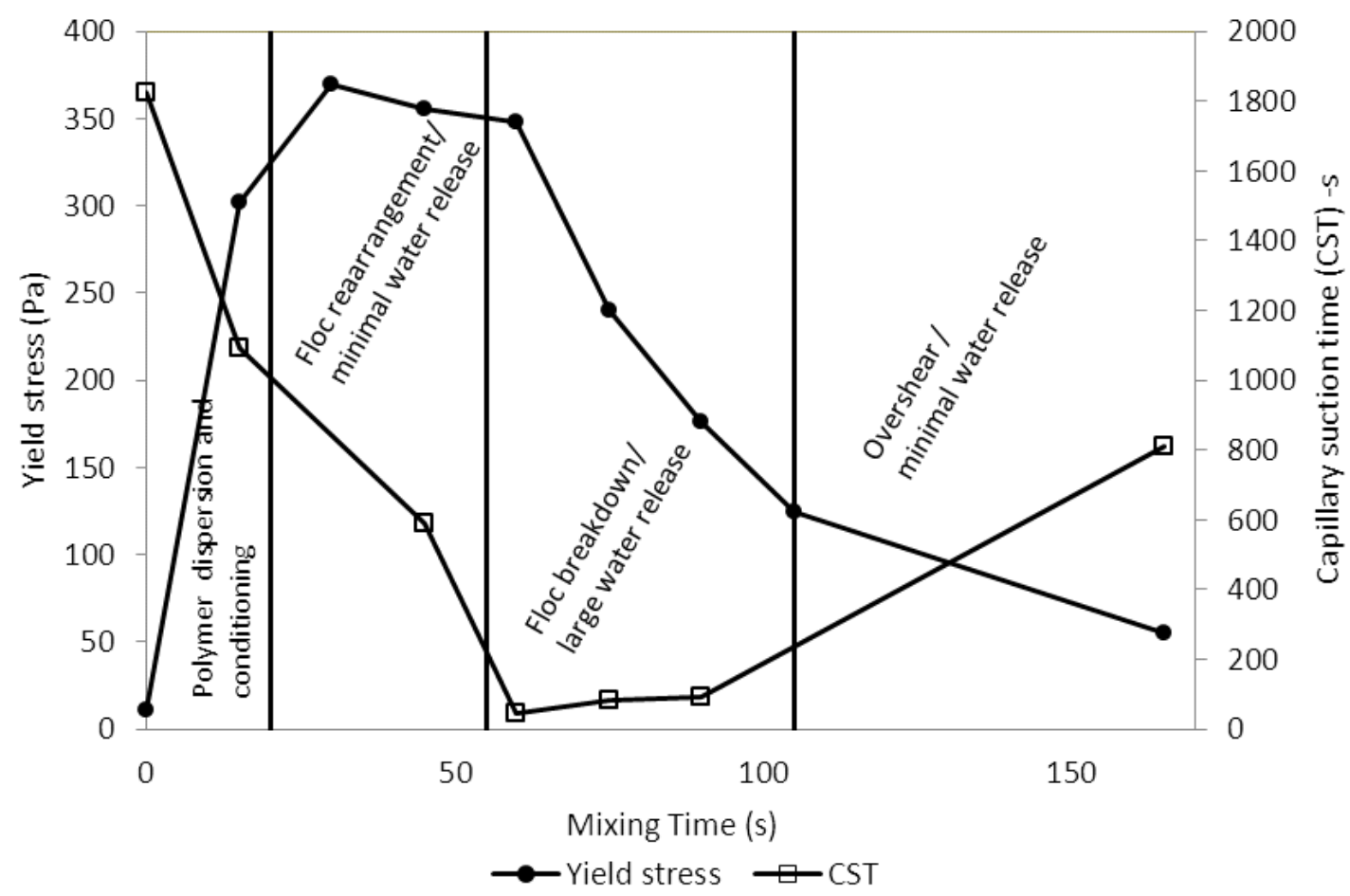

Figure 1 Shear progression curve of flocculated MFT highlighting four distinct stages

In summary, four distinct stages were identified and assembled into a 'shear progression curve':

- Stage 1 - Polymer dispersion or floc build-up stage defined by a rapid increase in yield stress as the polymer contacts the minerals and poor water release is achieved.

- Stage 2 - Floc rearrangement: a gel state of high shear yield stress which can be a plateau depending on the applied shear rate and \% solids of the MFT. The rates of floc build-up and breakdown in this stage appear to be roughly the same.

- Stage 3 - Floc breakdown/dewatering: a region of decreasing shear strength and floc breakdown where significant amount of polymer-free water is released.

- Stage 4-Floc overshear: an oversheared region characterised by rapidly decreasing shear strength where the material quickly reverts to an MFT state and releases very little water.

These stages are used to quantify the behaviour of polymer-dosed MFT and to compare behaviours under different shear regimes. The third stage is the target design basis for deposition. At an optimal dose of polymer with good initial dispersion into MFT, the mixture reaches a preferred permeability allowing for the release of free water. Without the right dose and good dispersion, the MFT tends to remain in the gel state and only dries by evaporation. This is highlighted in Figure 2 where the same MFT in the under-dosed ( $500 \mathrm{~g} /$ tonne) or the overdosed states $(1,000 \mathrm{~g} /$ tonne $)$ fails to release significant amounts of water despite developing significant yield stresses. A key advantage of the SNF polymer is the prolonged resistance to shear which allows operational flexibility when pipelining flocculated MFT to deposition cells. 


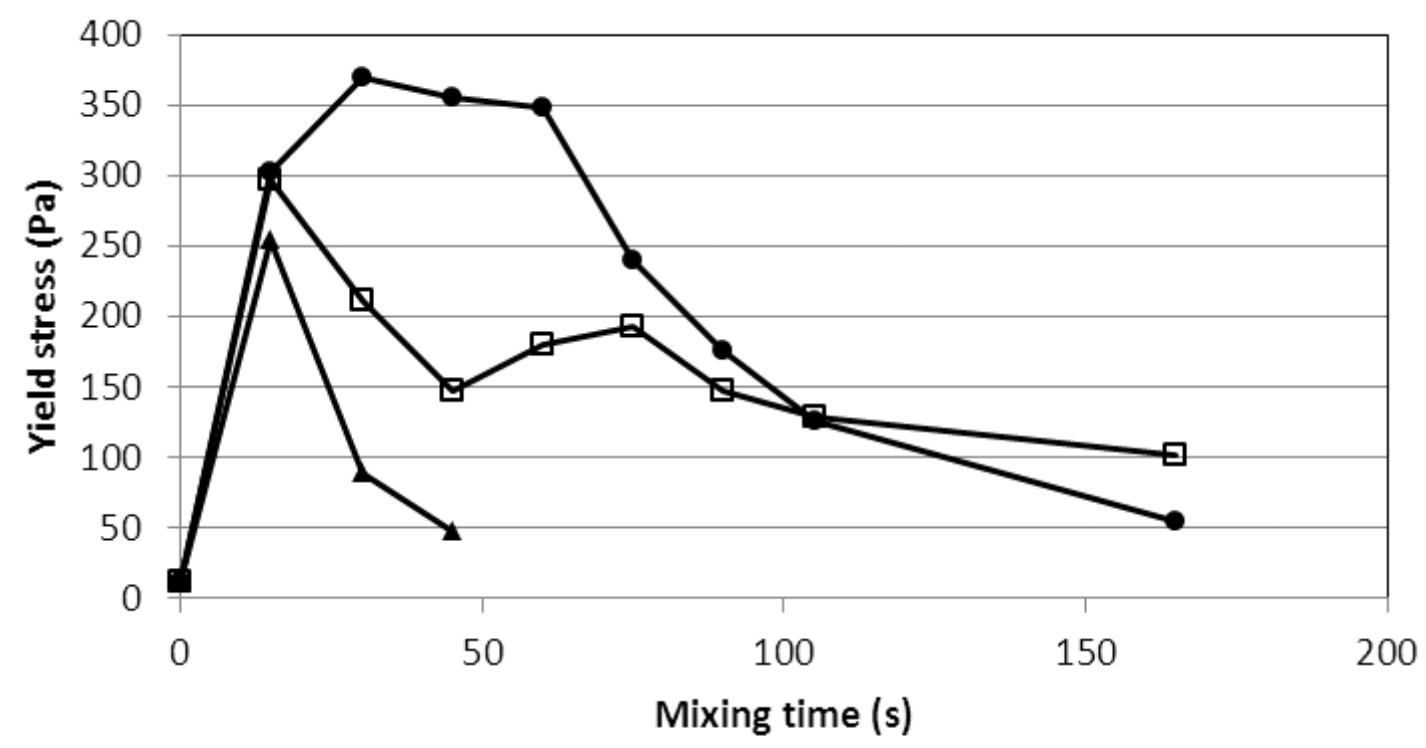

$\longrightarrow$ 500 g/tonne solid $\longrightarrow 800 \mathrm{~g} /$ tonne solid $\longrightarrow 1000 \mathrm{~g} /$ tonne solid

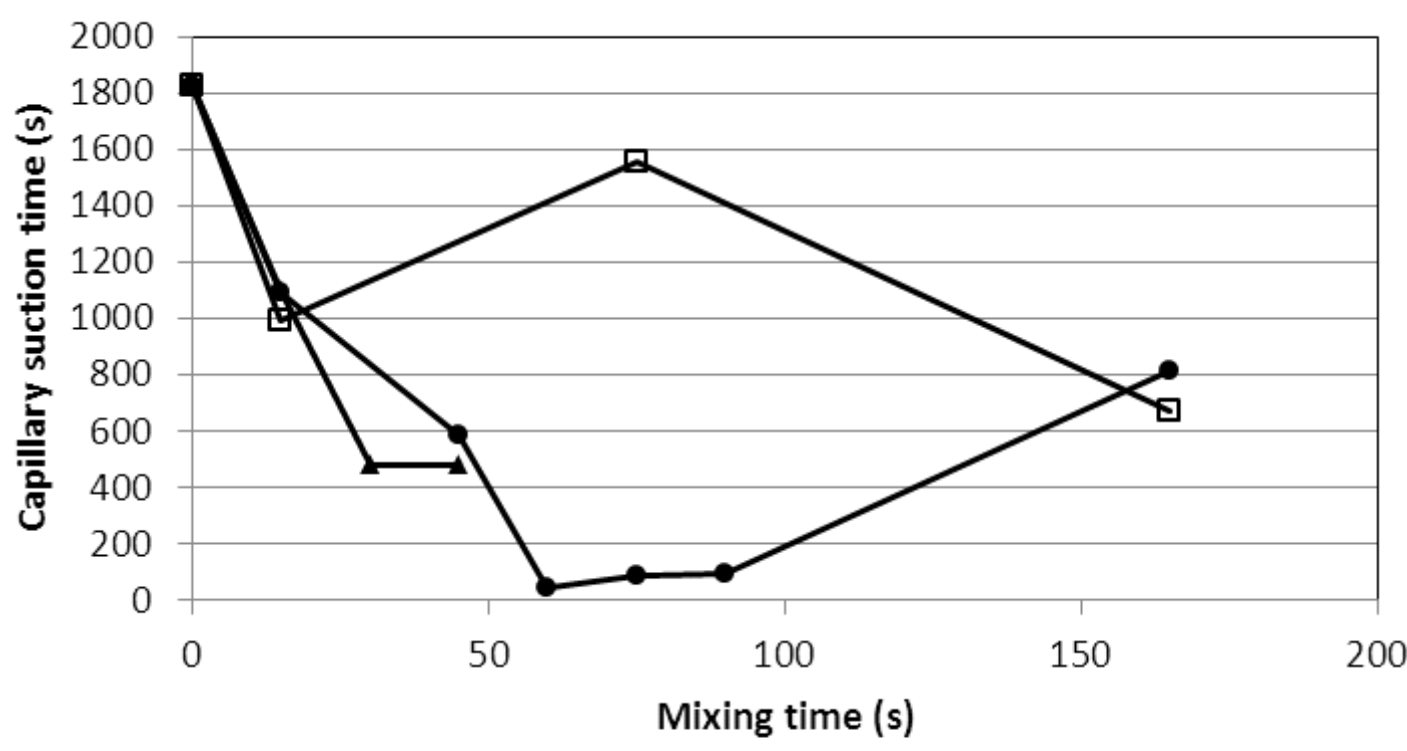

$\longrightarrow$-500 g/tonne solid $\longrightarrow$-800 g/tonne solid $\square-1000 \mathrm{~g} /$ tonne solid

Figure 2 Variation of polymer dosage with yield stress and water release. Neither the addition rates of 500 nor $1,000 \mathrm{~g} /$ tonne of solid released significant amounts of water

Shown in Figure 3 are the microstructures corresponding to different shear regimes in the optimally flocculated MFT in Figure 1. The MFT and flocculated slurries were flash dried to preserve the microstructure to some extent. Samples were platinum coated and examined in a scanning electron microscope. The starting MFT showed a more massive microstructure on drying and a greater tendency for the clays to stack along their basal planes in large booklets. This results in a low concentration of interconnected pores and poor dewatering. The middle micrographs in Figure 3 show microstructures exhibited by flocculated MFT in the second stage $\left(\sigma_{y}=383 \mathrm{~Pa}\right)$ at the onset of floc breakdown and water release. The microstructure is dominated by dense aggregates and randomly oriented clay platelets with more interconnected pores. The third set of micrographs $\left(\sigma_{\mathrm{y}}=86 \mathrm{~Pa}\right)$ show less massive aggregates and a more open structure most likely responsible for the large water release observed in the third stage. 


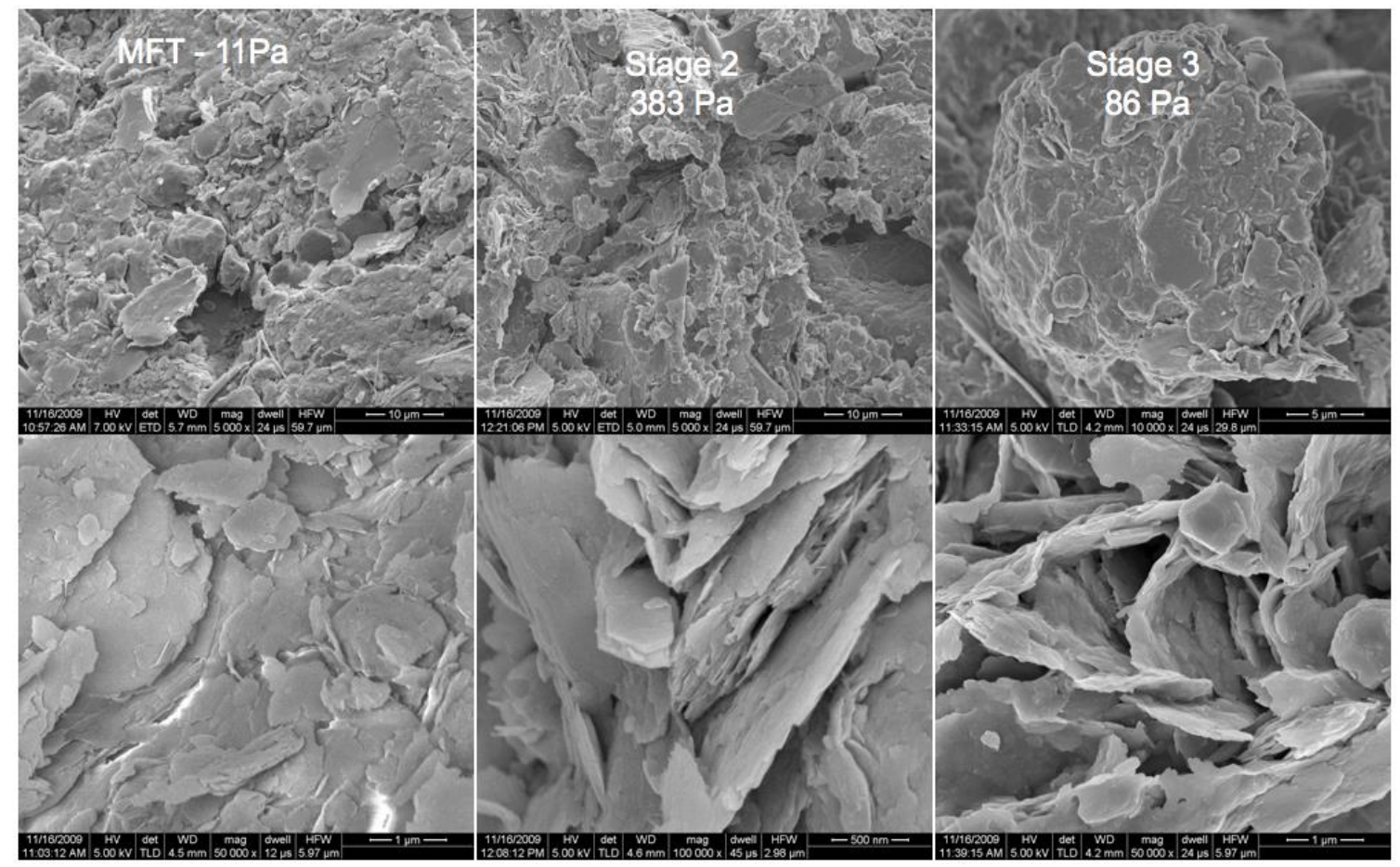

Figure 3 Scanning electron micrographs of $40 \mathrm{wt} \%$ MFT showing the fabric at different shear regimes (a) untreated MFT, (b) high yield strength (383 Pa), (c) dewatering stage (89 Pa)

MFT optimally dosed with polymer at 1,000 g/tonne of solids, with varying solids content were also investigated and are shown in Figure 4. As the solids content decreases polymer dispersion becomes easier. As one would expect, the maximum yield strength of the material also decreases with increasing water content. A substantial amount of water is released through treatment of lower solids content material (for example, $10 \mathrm{wt} \%$ settles to $20 \mathrm{wt} \%$ immediately) however the floc structure is weak and tends to be unable to stack on a deposition slope without being washed off.

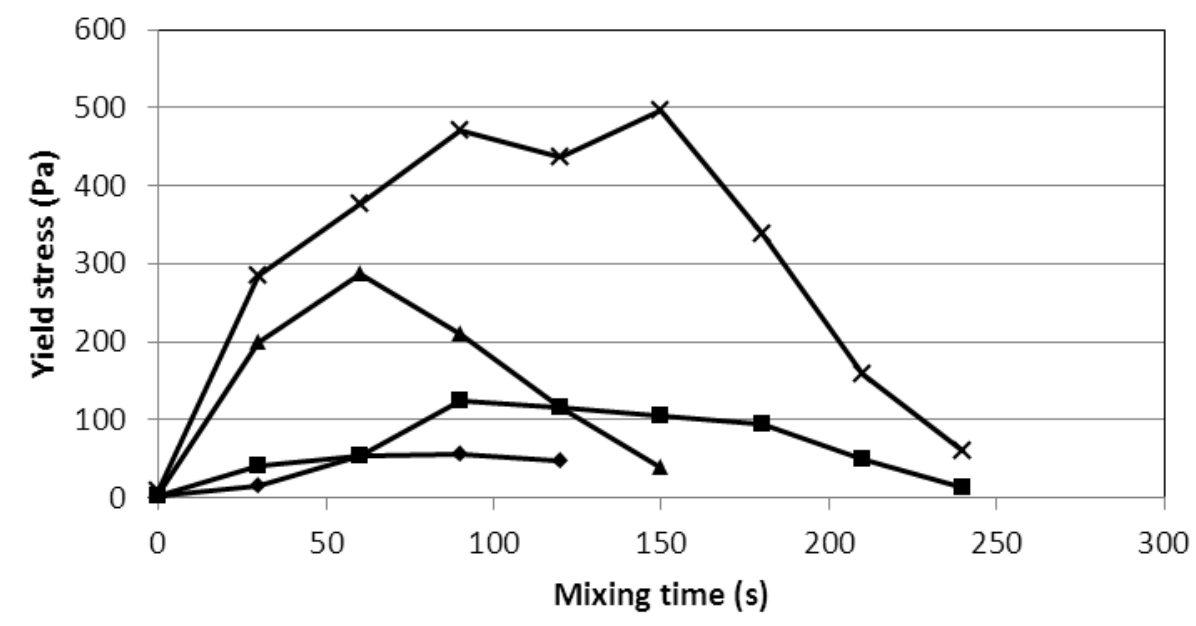

$\rightarrow 10 \mathrm{wt} \%$ solids $\rightarrow-20 \mathrm{wt} \%$ solids $\longrightarrow 30 \mathrm{wt} \%$ solids $\rightarrow 40 \mathrm{wt} \%$ solids

Figure 4 Shear strength progression for different weight $\%$ solids dosed at $1,700 \mathrm{~g} /$ tonne $(10 \mathrm{wt} \%$ solids), 1,600 g/tonne ( $20 \mathrm{wt} \%$ solids), $1,300 \mathrm{~g} /$ tonne ( $30 \mathrm{wt} \%$ solids) and 1,000 g/tonne (40 wt\% solids) respectively 
Further laboratory testing has shown that the strength gain and dewatering effects are possible with many anionic polymers, and are not limited to the particular formulation used in the first successful tests. Figure 5 compares a $40 \mathrm{wt} \%$ MFT optimally dosed with the SNF-polymer and a high molecular weight anionic polyacrylamide (aPAM) typically used for flocculating oil sands tailings. The optimum dosage for both polymers in terms of maximum water release was the same, and both were compared at two different shear rates, 220 and $32 \mathrm{~s}^{-1}$. Polymer dispersion and shear stress response of the SNF-polymer differ significantly from the aPAM. For the SNF-polymer, increasing the dispersion rate by increasing the mixer speed increases the yield stress instantaneously but the aPAM required additional mixing before the onset of flocculation. This decrease in the dispersion rate means that MFT treated with aPAM is more likely to stay in a gel state and not release as much water.

It is generally expected for an aPAM that a higher mixing energy will build up the yield stress rapidly but the floc breakdown also occurs at a faster rate. The lower viscosity of the SNF-polymer coupled with a high resistance to shear allow the flocculated MFT to be transported over long distances to deposition cells without significant floc breakdown.

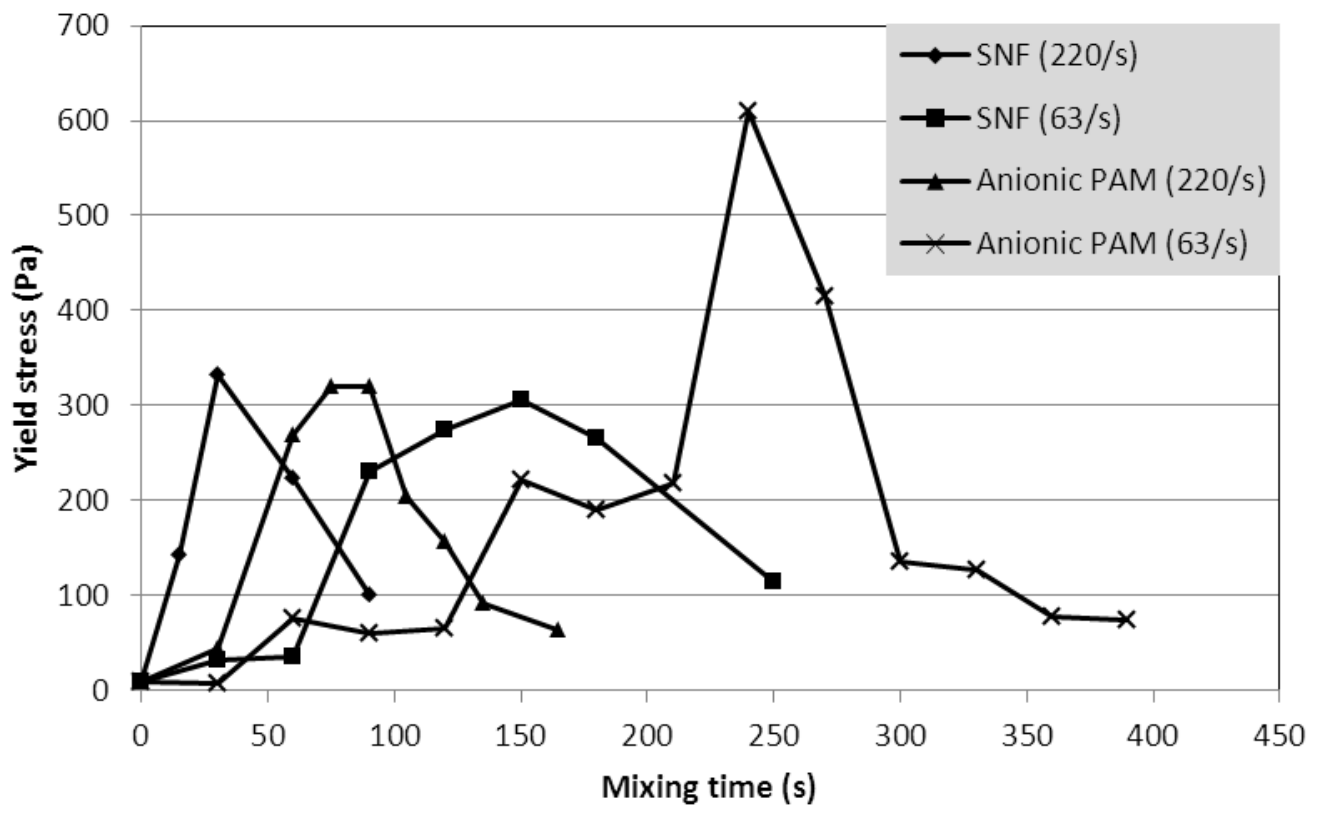

\section{Figure 5 Yield stress progression of MFT optimally dosed with SNF-polymer and a high molecular weight aPAM}

In order to optimise the behaviour of the flocculated material, it was found necessary to limit the variance in the shear energy applied to the various flocs which are created during mixing. This was achieved with an inline orifice injector system. The concept here was to inject the polymer as a "mist" through the orifice (Figure 6a) instead of a stream (Figure 6b). When injected into a turbulent back-flow regime as shown in Figure 6a, the polymer was evenly distributed and flocculation was occurring throughout the pipeline cross section within four pipe diameters of the injection point. This rapid dispersion allowed for precise control of the shear energies from the injection point to the point of deposition, and increased the percentage of the material that fell within the dewatering zone at the design point in the system. This fundamental behavioural understanding was key to the successful application of this technique, and allowed the results obtained from bench scale testing to be used in computational fluid dynamic (CFD) modelling and scaled up to field operations with some degree of confidence. 
(a)

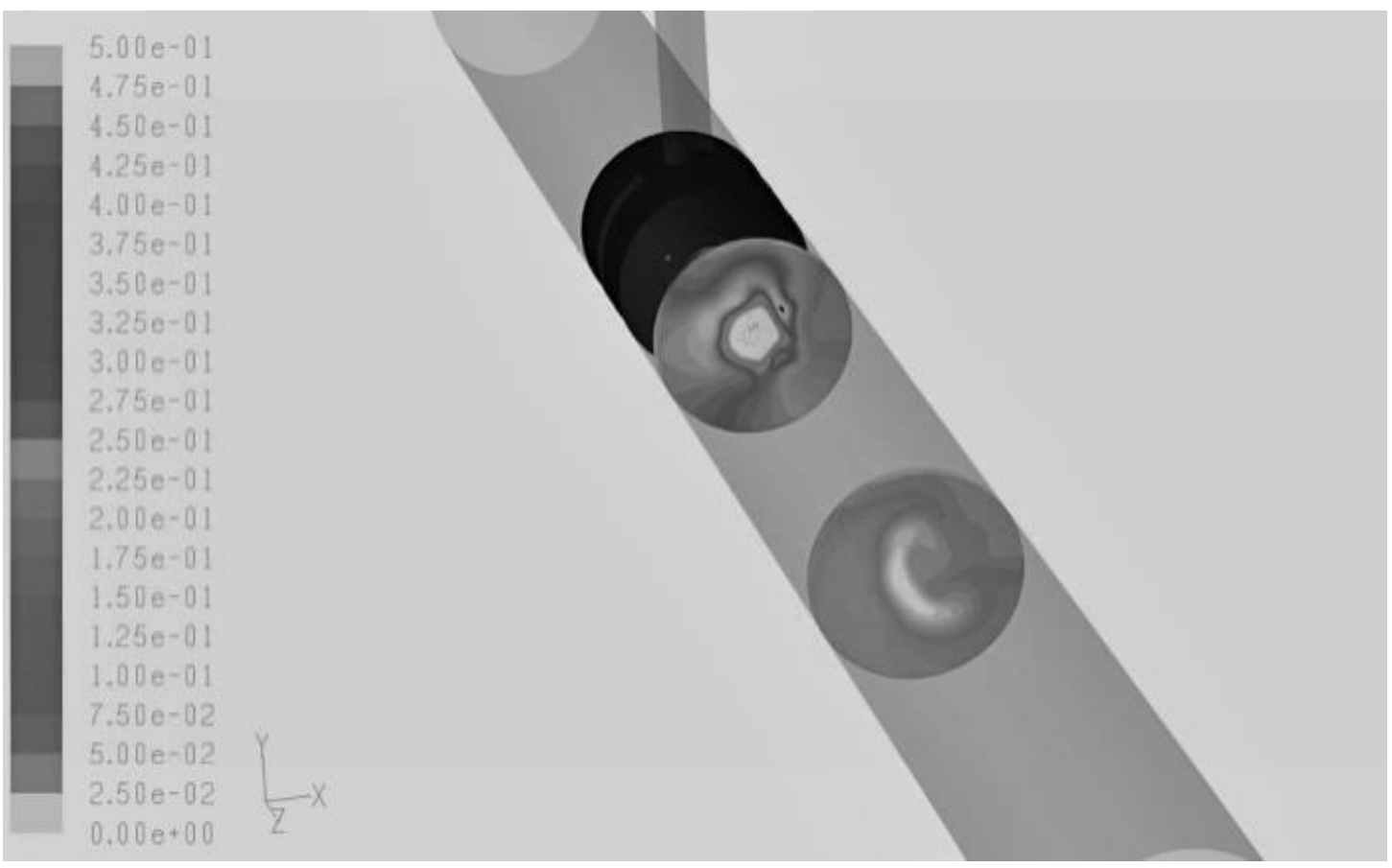

(b)

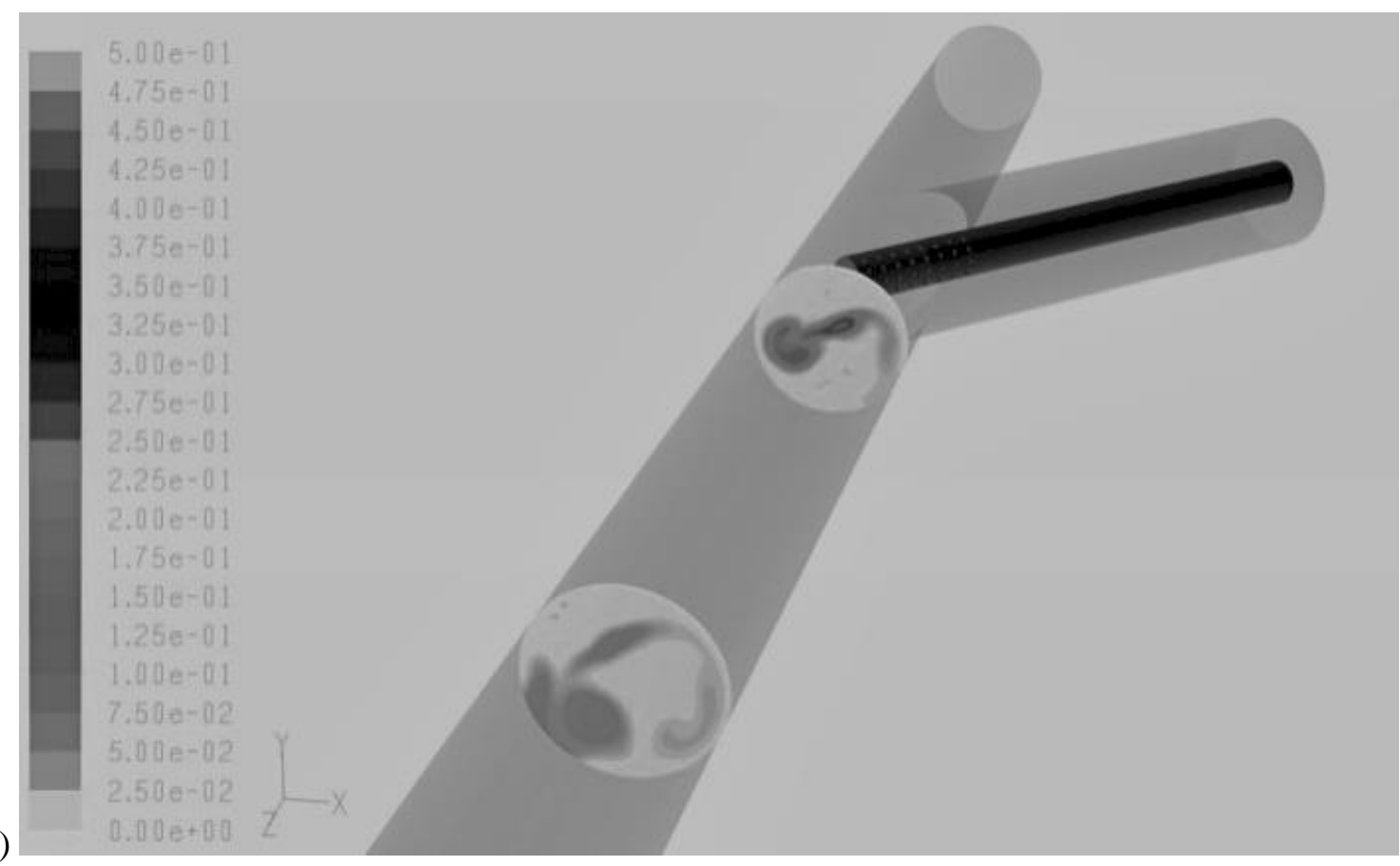

Figure 6 CFD model of (a) an in-line orifice injector showing good dispersion (polymer in light grey); and (b) a wand injection showing poor dispersion (polymer in dark grey)

\subsection{Pilot test for the determination of mixing parameters}

A $20 \mathrm{~m}$ long and $0.05 \mathrm{~m}$ diameter pipe loop fitted with the in-line orifice injector was used to investigate the shear response and dewatering behaviour of flocculated MFT (Swift et al., 2004; Heath and Koh, 2003; Thomas et al., 1999). Sample ports were fitted to two locations along the length of the pipe. Figure 7a shows that the yield strength progression in the pipe loop was similar to that observed in the laboratory jar mixer although the mixing energies were not directly comparable. MFT flows at $30 \mathrm{~L} / \mathrm{min}$ correspond to a mean velocity gradient of $22 \mathrm{~s}^{-1}$ compared to $63 \mathrm{~s}^{-1}$ in the bench scale test. Another test conducted at $100 \mathrm{~L} / \mathrm{min}$ $\left(176 \mathrm{~s}^{-1}\right)$ showed a more rapid floc build-up and breakdown similar to the $220 \mathrm{~s}^{-1}$ test in the jar mixer. Figure 7b shows flocculated MFT sampled at different locations during the test run for the MFT flowing at 
$30 \mathrm{~L} / \mathrm{min}$ optimally dosed at (1,000 g/tonne of solids). Data from the pilot and field tests are currently being used to develop a mixing model for process design and monitoring of the commercial scale MFT drying plant.

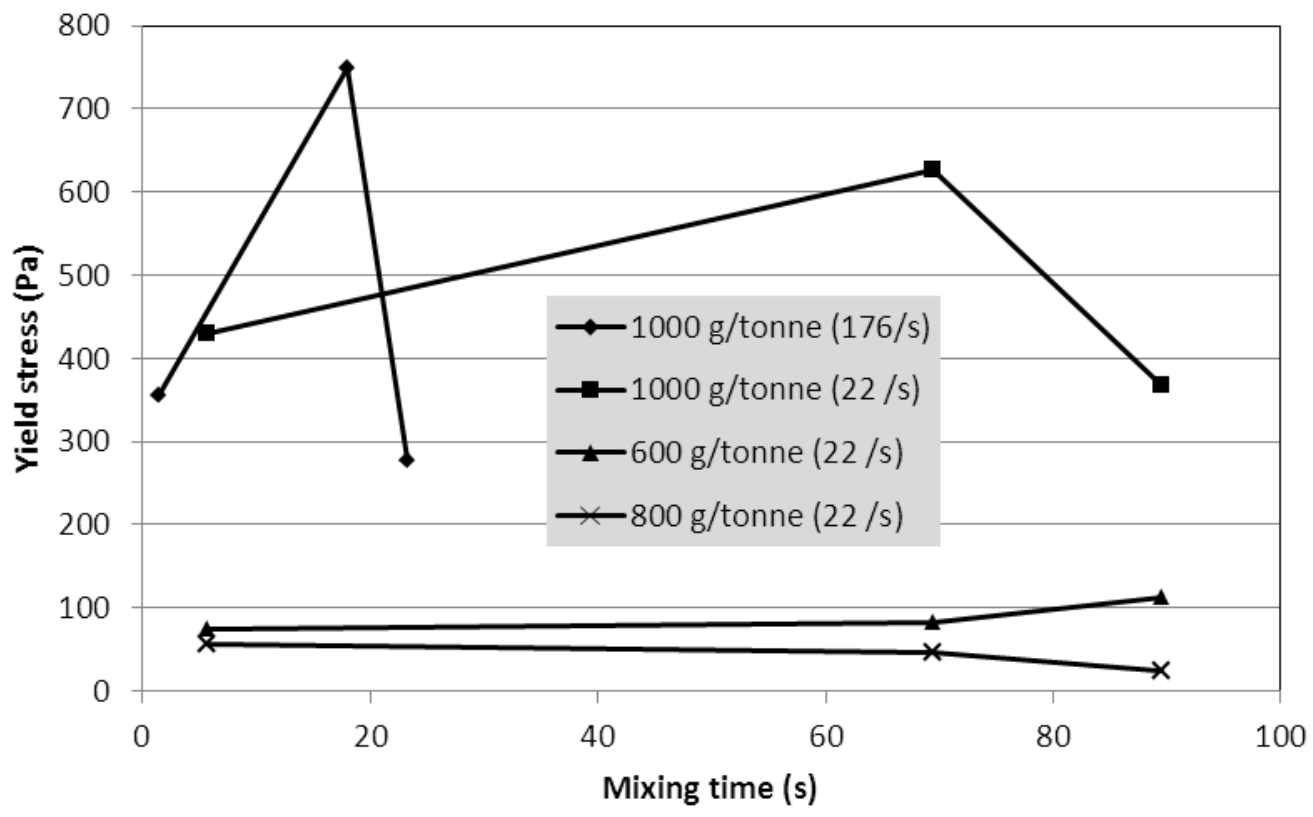

Figure 7a Shear progression curves of the pilot scale flocculated MFT (35 wt \% solid) during transport

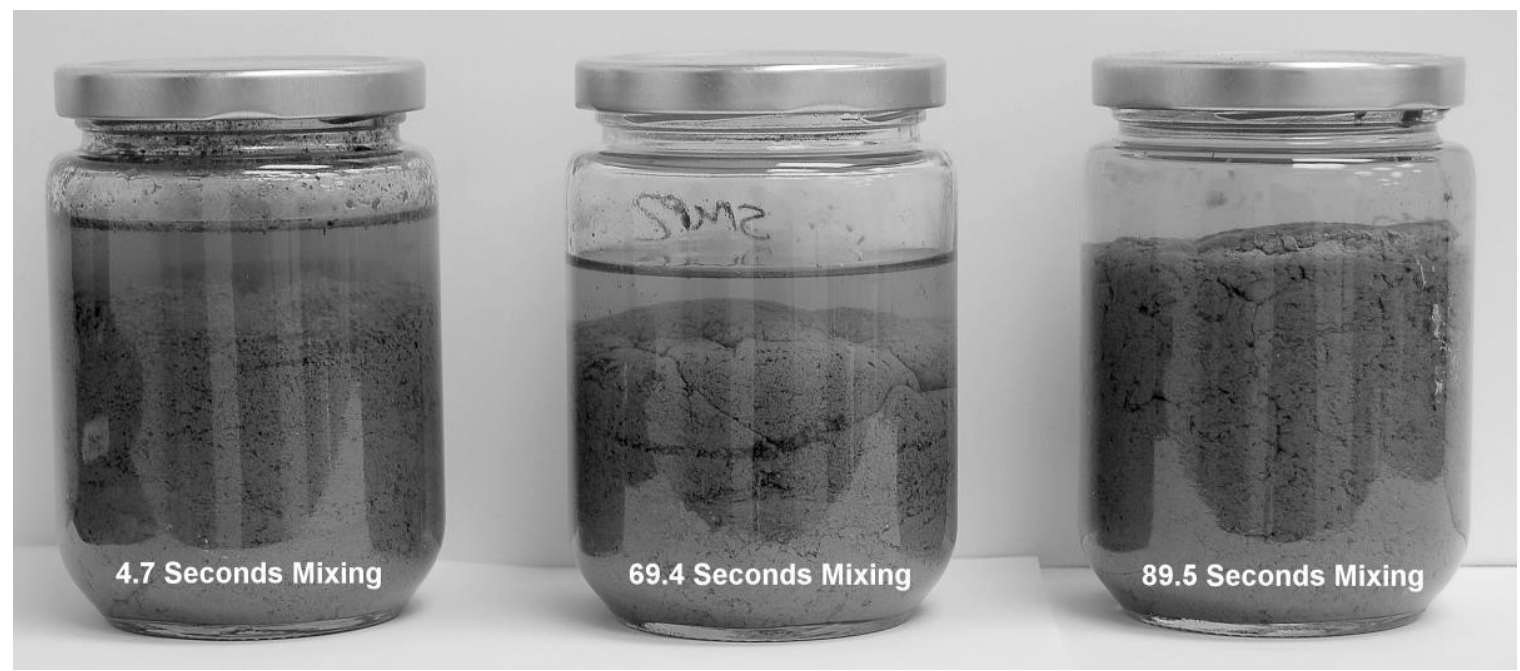

Figure 7b Jars containing samples taken at each sample point in Figure 7a during the 1,000 g/t $22 \mathrm{~s}^{1}$ test

\section{$4 \quad$ Field observations}

The rapid polymer dispersion by the orifice mixer caused the yield strength of flocculated material to increase very rapidly and results in the deposition of a two-phase fluid. This is shown in Figure 8 where the flocculated MFT and a separate water stream are observed at the discharge in one of the earlier pilot tests at Suncor Energy. 


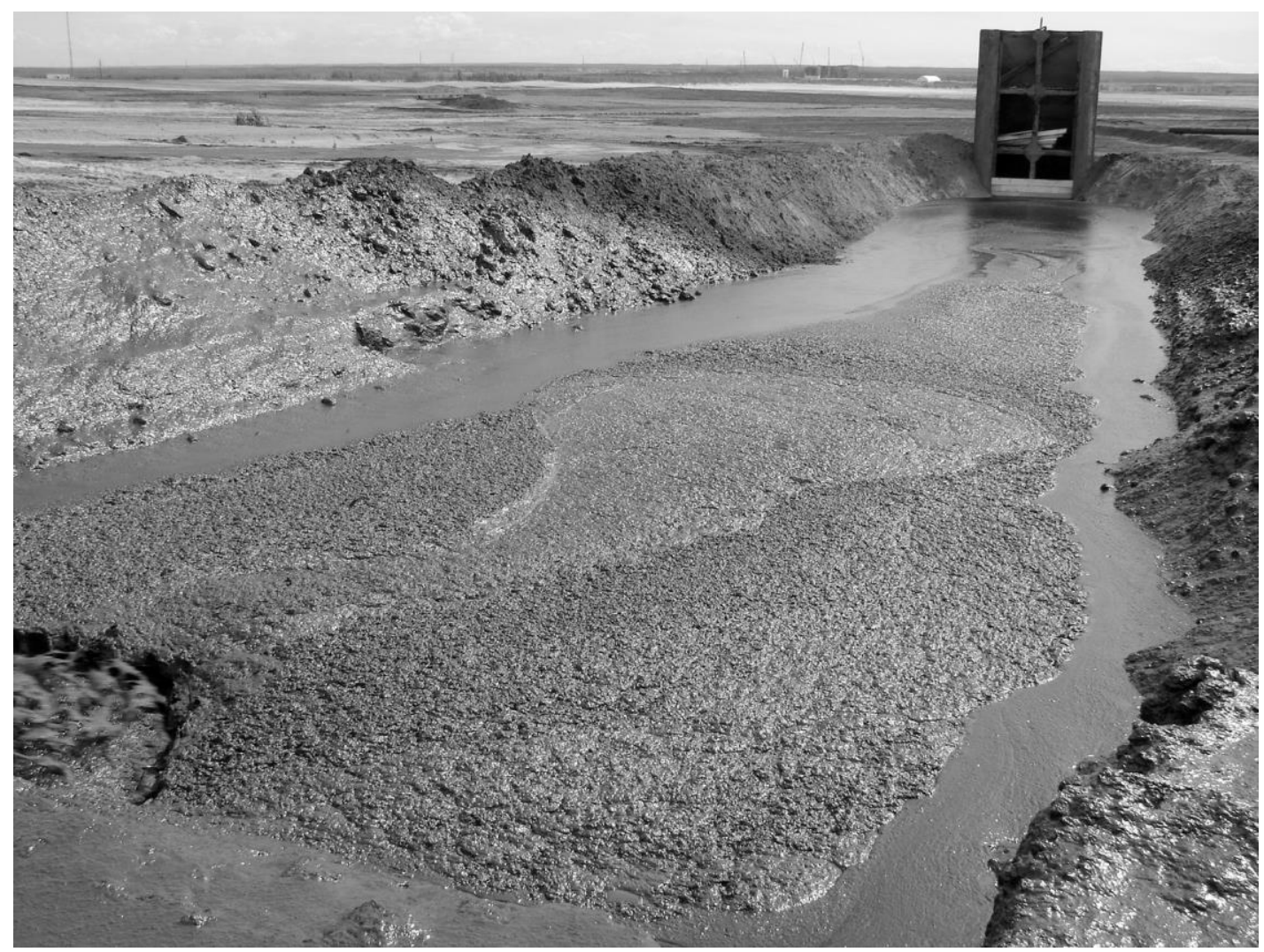

\section{Figure 8 Flocculated MFT discharged on a slope showing high yield strength material and water channelling around the discharge}

A scaled up version of the orifice mixer was investigated in the field with optimally dosed $35-40 \mathrm{wt} \%$ MFT flowing at $\sim 7,500 \mathrm{~L} / \mathrm{min}\left(32 \mathrm{~s}^{-1}\right)$ in $0.3 \mathrm{~m}$ diameter pipe, and deposited in cells at various distances from the injection point. Figure 9 shows the extent of water release for each cell, both from actual sampling after $24 \mathrm{hrs}$ and a capillary suction test conducted on the as-deposited flocculated MFT. The dewatering trend is analogous to the shear progression profile for the laboratory and pilot tests. Over 25\% of the MFT water was released immediately after injection up to $175 \mathrm{~m}$ from the injection point. Beyond this distance, the water release rate decreased rapidly and the flocculated material properties resemble MFT.

Further dewatering occurs in the deposition slopes through drainage enhanced by the slope, shrinkage and evaporation. The under mixed material deposited at roughly $7 \mathrm{~m}$ from the discharge was further dewatered by mechanically working the material to reach the floc breakdown stage where more water was released from the flocculated material. Aggressive mechanical working however could break the deposit structure resulting in lower permeability and a restricted water release. Once the permeable structure is broken, dewatering is limited to evaporative drying.

Shrinkage of the floc through dewatering and evaporation results in crack formation as shown in Figure 10. Deepening cracks allow for side drainage of release water into cracks down the slope. Typical deposits up to $20 \mathrm{~cm}$ lift were found to dry beyond $80 \mathrm{wt} \%$ solids in 6 days after which a subsequent lift could be placed. 


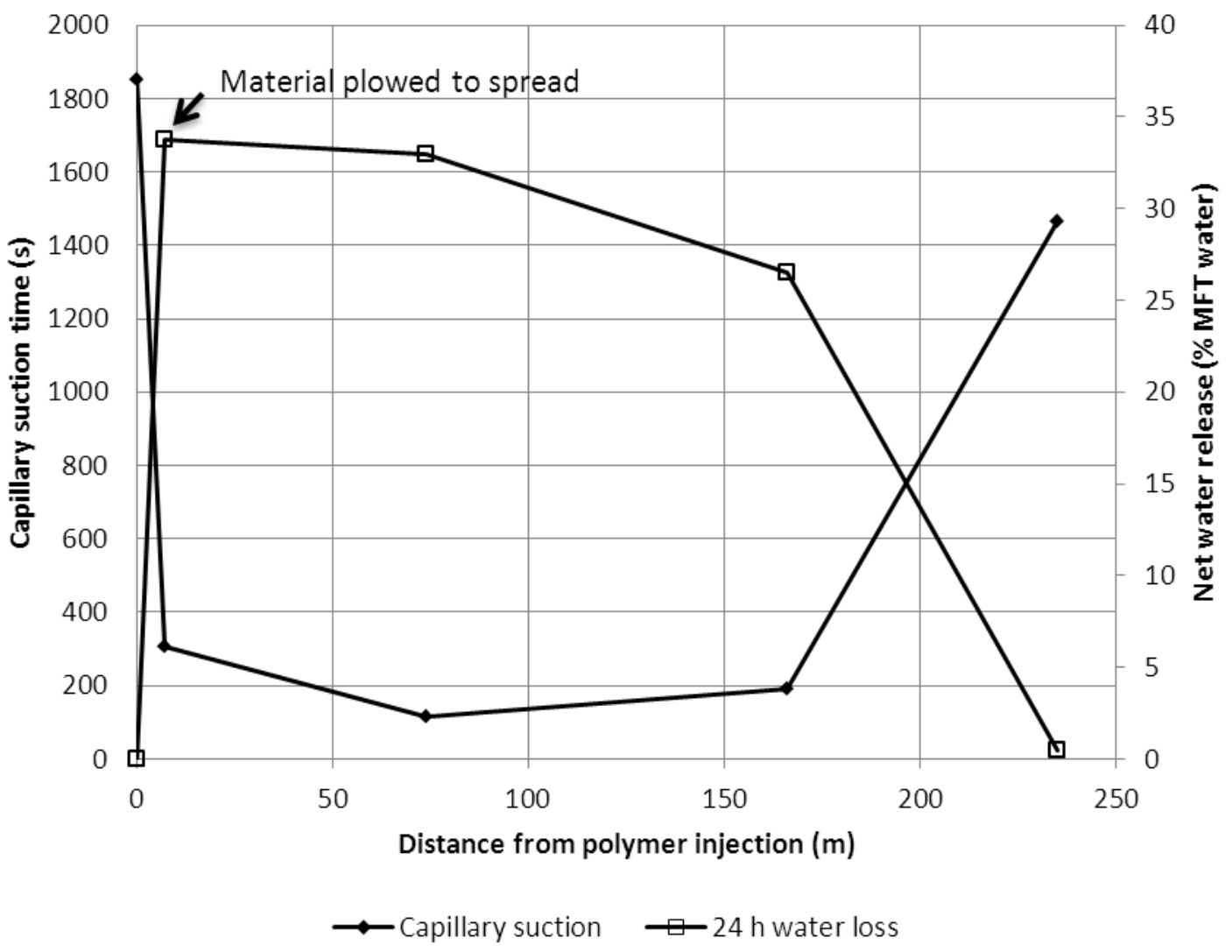

Figure 9 Water release rate of flocculated MFT at various distances from the injection point

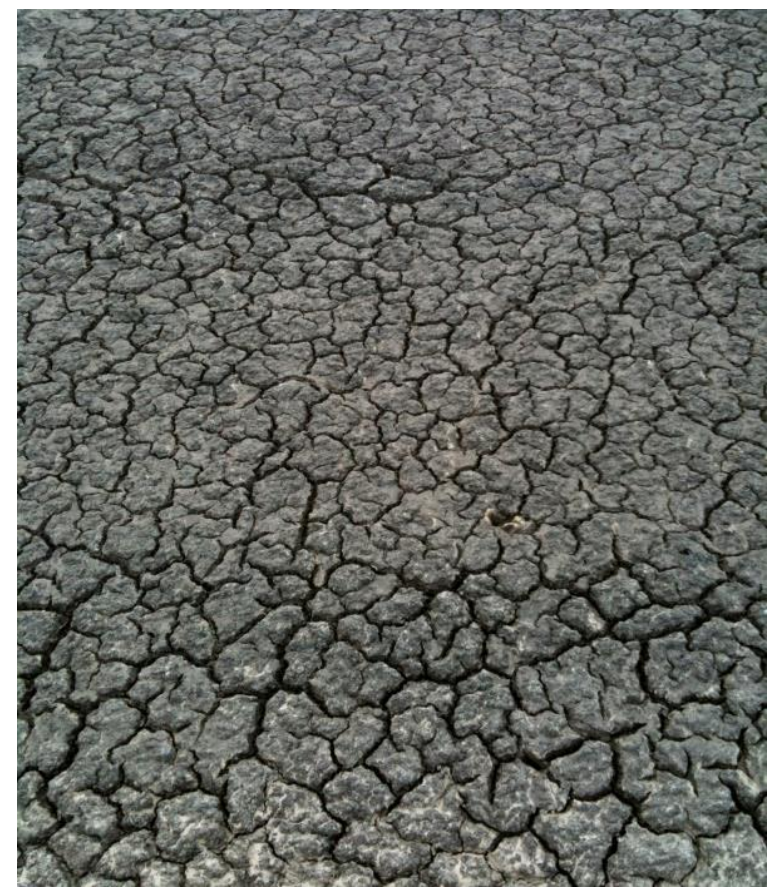

Figure 10 Crack formation in an optimally flocculated MFT after a few days

\section{Conclusions}

The technology presented here represents a step forward in polymer applications to fine tailings streams. It was discovered that the commonly used standard laboratory testing methods for the mixing of polymer into 
fluid tailings hid many of the strength gain and dewatering processes on which MFT Drying is now based. The use of the new polymer from SNF allowed an operational window sufficiently wide for these effects to be observed and utilised, but was not limited to this polymer formulation alone. This effect can be produced with many standard aPAM flocculants. In addition, findings from this programme include:

- Quick dispersion of the polymer within the MFT stream at the point of injection greatly increased the effectiveness of the process.

- Yield strength gain of a properly dosed mixture occurred as a function of shear energy applied to the system over time. This strength peaked, then decreased as the polymer strings were broken.

- Discharging the mixture at the appropriate point on the yield stress curve maximised dewatering in the deposit.

- Undershearing the mixture resulted in high yield strengths with greatly reduced dewatering performance.

- Overshearing the mixture resulted in reduced yield strengths as well as greatly reduced dewatering performance.

- Dewatering of the lifts after deposition was enhanced through the formation of shrinkage cracks. This allowed for continued dewatering beyond that possible with evaporation alone.

\section{Acknowledgements}

The authors wish to acknowledge the support of Suncor Energy Inc. including the Tailings Reduction Operations staff for their dedication and hard work, Paul Matthews and the Suncor legal team for their support in the development and documentation of the process, as well as the patience and foresight of the Suncor management team in seeing the potential of the technology. We also wish to acknowledge Scott Ramey and George Tichenor from SNF for their early work with the polymer development, Randy Mikula and the AST team at CANMET in Devon for their ongoing suggestions and trials of our processes and theories, and finally the COANDA team in Burnaby, British Columbia for their early laboratory and CFD support.

\section{References}

Golder Paste Technology Ltd. (Golder) (2007) Conceptual study on applying paste technology to oil sands tailings management at Suncor, Fort McMurray, 2007.

Heath, A.R. and Koh, P.T.L. (2003) Combined population balance and CFD modelling of particle aggregation by polymeric flocculant, in Proceedings Third International Conference on CFD in the Mineral Process Industries, CSIRO, 10-12 December 2003, Melbourne, Australia.

Jeeravipoolvarn, S. (2008) Deposition of inline thickened fine tailings, in International Oil Sands Tailings Conference, 7-10 December 2008.

Matthew, J. (2008) Past Present and Future Tailings Experience at Albian Sands, in International Oil Sands Tailings Conference, 7-10 December 2008.

Omotoso, O. and Mikula, R.J. (2004) High surface area caused by smectitic interstratification of kaolinite and illite in Athabasca oil sands, in Applied Clay Science, Vol. 25(1-2), pp. 37-47.

Spicer, P.T. and Pratsinis, S.E. (1996) Shear Induced flocculation: The evolution of floc structure and the shape and the size distribution at steady state, in Water Research, Vol. 30(5), pp. 1049-1056.

Swift, J.D., Simic, K., Johnston, R.R.M., Fawell, P.D. and Farrow, J.B. (2004) A study of the polymer flocculation reaction in a linear pipe with a focused beam reflectance measurement probe, International Journal of Minerals Processing, Vol. 73, pp. 103-118.

Thomas, D.N., Judd, S.J. and Fawcett, N. (1999) Flocculation Modeling: A review, Water Resources, Vol. 33(7), pp. 1579-1592.

Wells, P.S. and Riley, D. (2007) MFT drying - case study for the use of rheological modification and dewatering of fine tailings through thin lift deposition in oil sands tails, in Proceedings Tenth International Seminar on Paste and Thickened Tailings (Paste07), A.B. Fourie and R.J. Jewell (eds), 13-15 March 2007, Perth, Australia, Australian Centre for Geomechanics, Perth, pp. 271-284. 